\title{
OS CONTRATOS DE ARRENDAMENTO E PARCERIA NO BRASIL
}

\author{
Patrícia José de Almeida e Antônio Márcio Buainain
}

LAND LEASE AND PARTNERSHIP AGREEMENTS IN BRAZIL

\section{RESUMO}

ESTE ARTIGO PARTE DO DIÁLOGO EXISTENTE ENTRE DIREITO E ECONOMIA PARA ANALISAR OS CONTRATOS DE ARRENDAMENTO E PARCERIA No BRASIL. AdMITE-SE QUE a LEGISLAC̣ĀO PÁtRIA COLOCA ENTRAVES AO ESTABELECIMENTO DESSES CONTRATOS, ESPECIALMENTE NAQUELES QUE ENVOLVEM PRODUTORES MAIS POBRES. VALE-SE DE UM RESGATE HISTÓRICO DO PROCESSO DE CRIAÇÃO DO ESTATUTO DA TERRA PARA COMPREENDER O CONTEXTO QUE EMBALA O SURGIMENTO DO APARATO LEGAL ESPECÍFICO AOS CONTRATOS AGRÁRIOS. ADEMAIS, APRESENTA AS PRINCIPAIS CARACTERÍSTICAS DOS CONTRATOS, POR EXEMPLO, PRAZOS, FORMA DE PAGAMENTO, DIREITO DE PREFERÊNCIA, INDENIZAÇÃO POR BENFEITORIAS. VERIFICA-SE QUE A REGULAMENTAÇÃO DOS CONTRATOS DE ARRENDAMENTO E PARCERIA NASCE EM MEIO A INTERESSES PONTUAIS E CONTRADITÓRIOS. AS CLÁUSULAS CONTRATUAIS NEM SEMPRE ASSISTEM A PARTE ECONOMICAMENTE MAIS FRÁGIL. CONCLUI-SE QUE O USO MAIS INTENSO DOS CONTRATOS AGRÁRIOS NO PAÍS DEPENDE DE MUDANÇAS NA LEGISLAÇÃO, DE MODO QUE ATENDA AS CONDIC̣ÕES SOCIOECONÔMICAS DOS ARRENDATÁRIOS E PARCEIROS, SOBRETUDO, DOS PEQUENOS PRODUTORES.

\section{PALAVRAS-CHAVE}

Contratos; Arrendamento; Parceria; Legislação Agrária; BRASIL.

\section{ABSTRACT}

THIS ARTICLE USES THE EXISTING DIALOGUE BETWEEN LAW AND THE ECONOMY TO ANALYZE LEASING AND SHARECROPPING CONTRACTS IN BRAZIL. IT IS A FACT THAT NATIONAL LEGISLATION CREATES OBSTACLES TO ESTABLISHING THESE CONTRACTS, ESPECIALLY THOSE THAT INVOLVE SMALL, POOR PRODUCERS. A LOOK AT THE HISTORY OF THE PROCESS OF CREATING THE STATUTE OF THE SOIL HELPS UNDERSTAND THE CONTEXT THAT GAVE RISE TO THE SPECIFIC LEGAL APPARATUS FOR AGRARIAN CONTRACTS. FURTHERMORE, IT PRESENTS THE MAIN CHARACTERISTICS OF THESE CONTRACTS, FOR EXAMPLE, DEADLINES, PAYMENT METHODS, PREFERENCE RIGHTS AND COMPENSATION FOR IMPROVEMENTS. IT IS NOTICED THAT THE ENFORCEMENT OF LEASING AND SHARECROPPING CONTRACTS ARISES IN THE MIDST OF STRICT AND CONTRADICTORY INTERESTS. THE CLAUSES IN THE CONTRACTS DO NOT ALWAYS BENEFIT THE ECONOMICALLY MORE FRAGILE PARTY. IT IS CONCLUDED THAT MORE INTENSIVE USE OF AGRARIAN CONTRACTS DEPENDS ON LEGISLATIVE CHANGES THAT ATTEND THE SOCIO-ECONOMIC CONDITIONS OF LEASERS AND SHARECROPPERS, ABOVE ALL, THE SMALL PRODUCERS.

\section{KEYWORDS}

CONTRACTS; LEASING; SHARECROPPING; AgRARIAN LEGISLATION; BRAZIL.

\section{INTRODUÇÃO}

A relação Direito e Economia é antiga. Adam Smith e Jeremy Benthan, no século XVIII, já estudavam a relevância da análise interdisciplinar ou multidisciplinar de fatos sociais. A teoria smithiana procurava mostrar os efeitos econômicos oriundos 
da formulação das normas jurídicas, enquanto a teoria bethaniana procurava associar legislação e utilitarismo. Nos séculos XIX e XX, economistas como Pareto, Kaldor e Hicks passaram a enveredar pelos modelos normativos propostos pelo Direito. Para o primeiro, a transferência de bens ocorre de quem os valoriza menos a quem lhes oferece mais valor. Os outros dois sugerem que as normas devem ser desenhadas de forma a gerarem o máximo de bem-estar para a maioria da sociedade. Grosso modo, as áreas em que essa interdisciplinaridade se demonstra intensa abarcam matérias como propriedade, contratos e mercados (SZTAJN, 2005).

Sob o ângulo da moderna teoria econômica, notoriamente Nova Economia Institucional e Análise Econômica do Direito, os direitos de propriedade adquiriram múltiplas dimensões analíticas.

Em primeiro lugar, é oportuno dizer que, em ambas vertentes, o objetivo geral é analisar como a definição dos direitos de propriedade, em contextos específicos, pode influenciar o comportamento dos agentes econômicos. Considera-se que direitos de propriedade seguros e mais bem definidos, inclusive o direito de vender ou transferir a propriedade, contribuem para que a alocação dos recursos seja feita de tal maneira que gere maior bem-estar. Todavia, o objeto de estudo e o enfoque das duas vertentes são diferentes. Na Análise Econômica do Direito, o objeto de estudo são as leis formais e o intuito é buscar na Teoria Econômica os elementos que possam auxiliar na elaboração de leis para induzir os agentes a agir mais eficientemente. Verifica-se claramente um enfoque normativo, isto é, procura-se fazer recomendações de como a Economia e a sociedade deveriam ser organizadas a fim de atingir um nível mais elevado de eficiência.

Ao passo que a Nova Economia Institucional, além das leis, abrange desde instituições informais e não escritas a costumes e normas. Esta vertente tem o objetivo de explicar a realização e a persistência de resultados ineficientes no sistema econômico, dado que as instituições não conduzem os agentes a situações mais eficientes, como se observa no caso de deficiência na definição dos direitos de propriedade. Há um enfoque positivo, ou seja, o objetivo é explicar o que efetivamente causa o comportamento dos agentes na Economia (SZTAJN et al, 2005).

Pode-se destacar três dimensões dos direitos de propriedade. A primeira deve-se aos trabalhos seminais de Ronald Coase, The nature of the firm (1937) e The problem of social cost (1960), os quais deram novo tratamento ao tema da propriedade. O autor argumentou que não são apenas os bens-objeto do Direito que são negociados, ou seja, os direitos de uso, usufruto e abuso sobre o bem; mas os direitos de propriedade sobre as dimensões de bens (os certificados de qualidade, por exemplo). Coase admitia que, na ausência dos custos de transação, os agentes poderiam realocar, eficientemente, os direitos de propriedade, pois os agentes negociariam a transferência dos direitos a custo zero. ${ }^{1}$

North (1994), a partir dos estudos de Coase, focalizou o papel das instituições para o desenvolvimento socioeconômico e o impacto destas no controle dos custos 
de transação e na alocação dos direitos de propriedade. As instituições seriam os instrumentos responsáveis pela execução das normas (os tribunais, por exemplo), assim como as regras formais e informais (legislação, costumes etc.). Fala-se que o autor deu à discussão dos direitos de propriedade um tom macroinstitucional (segunda dimensão).

Denominada de microinstitucional, a terceira dimensão, cujo representante principal é Williamson (1989), parte do papel dos direitos de propriedade para entender as organizações. Isto é, estuda a influência da alocação dos direitos de propriedade sobre a eficiência e o desempenho das organizações. Supõe que o ambiente institucional está dado e analisa o comportamento dos agentes no desenho dos contratos e, em certa medida, na estrutura da firma.

No âmago deste debate, considera-se que o ambiente institucional, expresso nos direitos de propriedade e contratos, coloca entraves à prática mais intensa do arrendamento e da parceria no Brasil. O objetivo central deste artigo é analisar os contratos agrários no país. Admite-se que a legislação pátria, tal qual está instituída, desfavoreceria o estabelecimento de contratos que envolvem produtores sem ou com pouca terra para produzir. Embora a propriedade privada da terra esteja bem protegida no texto constitucional, a própria desigualdade social e concentração da propriedade da terra introduziram elementos de instabilidade que restringiu a prática de relações contratuais entre proprietários e pequenos produtores. Ou seja, a própria legislação parece "moldar-se" ao perfil de um produtor mais capitalizado.

A fim de atingir nosso propósito, estruturou-se o artigo em 4 seções, incluindo esta introdução e a conclusão. A seção 1 retrata o contexto histórico da elaboração do Estatuto da Terra, regulamentação basilar dos contratos de arrendamento e parceria. A seção 2, subdividida em 5 subseções, trata das principais características e regras que ditam os contratos de arrendamento e da parceria, objeto central do artigo. $\mathrm{Na}$ última seção são apresentadas as considerações finais.

\section{Antecedentes históricos: A ORIGEM do MARCO LEGAL}

Até a metade do século XVII, a apropriação das terras obedecia às Ordenações do rei de Portugal. A concessão de sesmarias a particulares tinha vários objetivos, desde estimular a utilização produtiva que gerava receitas para a Coroa, reduzir a ociosidade das terras, até assegurar a ocupação como estratégia de proteção contra a cobiça dos demais países que participavam do processo de expansão territorial. Neste sentido, as Ordenações eram claras: se o senhorio não cultivasse suas terras nem desse a outros para fazê-lo, perdia o direito a elas. As terras devolutas eram distribuídas aos interessados em lavrar e aproveitar as mesmas (SILVA, 1996). ${ }^{2}$

Pettersen e Marques argumentaram que "houve razões de ordem econômica para o surgimento dos contratos de arrendamento e parceria no Brasil” (1977, p. 19). Já por volta de 1850, antes da abolição da escravatura, notava-se um prelúdio dessas relações, 
que se intensificaram a partir da proibição do tráfico de escravos e da campanha abolicionista. À época da passagem para o trabalho livre, era elevada, principalmente no Nordeste, a presença de produtores de subsistência, que ocupavam as franjas das grandes propriedades, como parceiros e ou posseiros; também se registra a migração de produtores em busca de novas terras desocupadas. A mineração promoveu o deslocamento da população para o cultivo de subsistência e a pecuária. No Sul, iniciava a formação de pequenas propriedades. ${ }^{3}$

Ao contrário do que ocorreu nos Estados Unidos, no Brasil a extinção da escravatura e a introdução do trabalho deu-se sob as regras da Lei da Terras, que afirmava o direito dos proprietários e restringia o acesso dos homens livres às terras devolutas ao estabelecer a compra junto ao governo como meio de adquirir terra. Neste contexto, além de dinheiro - escasso para os pequenos produtores de subsistência -, era preciso vínculos com os governantes responsáveis pela venda das terras. A restrição ao acesso dos pequenos à terra favoreceu o florescimento dos contratos de arrendamento e parceria em todo o país, podendo-se arrolar três fatores para explicar a motivação dos proprietários: i) era uma forma de o proprietário colocar as terras em utilização, essencial para conservar a propriedade; ii) mecanismo de ajuste à carência de alimentos erguida pela monocultora; iii) em muitos locais era praticamente a única via de substituição do trabalho escravo, visto que parecia quase impossível a existência do trabalho assalariado naquele tempo na sociedade brasileira (PETTERSEN; MARQUES, 1977). ${ }^{4}$

Esses contratos constituíram, por um lado, a solução econômica para os proprietários de terras enfrentarem os problemas de falta de mão de obra. Serviram, por outro lado, para atender a procura de terras dos imigrantes no país, que viam na parceria uma forma de acumular riquezas e uma etapa para se tornar proprietários. Apesar de as desvantagens dessas relações contratuais serem notórias, o surgimento dos contratos de arrendamento e parceria contribuiu para conciliar os interesses dos proprietários e dos imigrantes.

Em 1916, com a promulgação do Código Civil brasileiro, essas relações contratuais passaram a ser juridicamente ordenadas pelas disposições especiais aos prédios rústicos (arrendamento rural) nos arts. 1.211 a 1.215 e à parceria rural (agrícola e pecuária) nos arts. 1.410 a 1.423 . A regulamentação, no entanto, mostrava-se claramente falha para disciplinar os conflitos entre o proprietário da terra e o produtor. O sistema implantado apresentava forte influência urbana e era deficiente no que se refere, sobretudo, ao caráter social do problema. Pode-se depreender que o legislador não atentou para o fato de proteger a parte mais débil do contrato, como se proprietário e arrendatário ou parceiro-outorgado fossem economicamente iguais.

Camarço (2001) ressaltou que os contratos agrários no Código Civil enfocaram a livre convenção das partes (pacta sunt servanda). A carga excessiva de liberalidade na contratação passou a reforçar uma estrutura fundiária concentradora e uma situação 
de injustiça social. Um exemplo emblemático disso é a meação, em que o proprietário só entrava com um dos fatores de produção, a terra, e o produtor com o seu trabalho e todas as despesas do processo produtivo mais os riscos inerentes à atividade agrária. A divisão do lucro, todavia, era meio a meio.

Os especialistas (i.e., agraristas) indicam que se pode encontrar o cerne deste problema entre os princípios gerais dos contratos, em particular, da "autonomia da vontade”. Oliveira (1988) realçou que a ideia do contrato como expressão da autonomia da vontade advém do Estado liberal. O liberalismo e, concomitantemente, a ascensão da burguesia ao poder econômico, político e social, permitiu a exacerbação do individualismo. Essa ideologia teve repercussão no Código Civil Francês (ou Código Napoleônico) de 1804. Este, por sua vez, exerceu intensa interferência sobre os ordenamentos jurídicos de vários países, onde havia um predomínio irrestrito da doutrina da autonomia da vontade e a plena liberdade de contratar.

De acordo com a autora, a pressuposição da igualdade de todos perante a lei dava total liberdade de contratar. Ademais, a propriedade da terra ampliou-se àqueles que possuíssem poder econômico para comprá-la. Em outras palavras, o proprietário podia, dentro de uma visão individualista, conferir à propriedade o uso que lhe fosse conveniente, ou, simplesmente, deixar à mercê da natureza. Com a queda do liberalismo, e as complexas mudanças nas relações econômicas, políticas e sociais, tornou-se latente limitar a autonomia da vontade a fim de coibir os abusos oriundos da liberdade de contratar. A sociedade do século XX passou a buscar em valores de justiça social ou distributiva uma forma de equilíbrio e harmonia nas relações jurídicas.

Ao longo do tempo, no Brasil, a deficiência das normas contribuiu para o crescimento da desigualdade da distribuição da propriedade da terra, a qual não só aprofundou o problema econômico da ineficiência produtiva, mas também alcançou uma dimensão social e política. Os movimentos populares aumentaram bastante, passaram a reivindicar a legalização das relações trabalhistas no campo ${ }^{5}$ e a realização da reforma agrária (PRADO JR., 1979).

O país carecia de:

[...] uma legislação especificamente agrária que disciplinasse a matéria, sem dissociá-la da realidade social, tornava-se cada vez mais premente à medida que profundas transformações operavam-se no meio rural. As crises que abalaram nossa agricultura, nosso país e o mundo todo, de modo geral, impunham a necessidade de substituição das normas fundamentadas na doutrina da autonomia da vontade (e que, na realidade, só protegiam os interesses do proprietário), por outro, que atentassem para os aspectos sociais do problema, visando antes de tudo o homem, e, a seguir, o uso adequado da terra, a preservação de recursos naturais, respeitando o princípio da função da propriedade (HIRONAKA, 1990, p. 100-1). 
Levar a cabo as aspirações da população exigia mudanças na Constituição, particularmente no que diz respeito à desapropriação por interesse social, cujo pagamento deixaria de ser prévio e em dinheiro (GUEDES PINTO, 1995). Em 31 de março de 1964, aconteceu o golpe de Estado. Neste cenário de euforia, o governo militar instituiu o Estatuto da Terra (Lei n. 4.504). Mais do que uma lei de reforma agrária, o Estatuto visava promover o desenvolvimento rural. Este objetivo alinhou-se perfeitamente às propostas da Comissão Econômica para a América Latina (Cepal), que apregoava a urgência da modernização da agricultura dos países latino-americanos a fim de superar sua situação de subdesenvolvimento.

É importante mencionar que o texto final do Estatuto da Terra ficou composto de quatro partes: Título I (Disposições Preliminares), Título II (Da Reforma Agrária), Título III (Da Política do Desenvolvimento Rural) e Título IV (Das Disposições Gerais e Transitórias). O grupo de trabalho responsável, sob coordenação do Ministro do Planejamento, declarou que o objetivo era elaborar uma lei de reforma agrária, entretanto, a conjuntura política da época obrigou-os a incluir a questão da política agrícola.

Veja que os dispositivos legais e reguladores da nossa estrutura agrária brasileira nascem em um contexto marcado por interesses pontuais e conflitantes. O texto divide explicitamente as medidas de reforma agrária (Título II) daquelas de política agrícola. Assim sendo, temas complementares à reforma agrária foram tratados separadamente, o que evidencia os dois campos de atuação da lei. A título de ilustração, pode-se citar os contratos agrários, a tributação da terra e colonização sob os Títulos I e III (GUEDES PINTO, 1995).

Pode-se falar que as leis e os decretos posteriores passariam a incorporar as adaptações, ditas "necessárias", na legislação para lidar com o problema agrário do país. A Lei n. 4.947, de 6 de abril de 1966, versava sobre o sistema de organização e funcionamento, sob tutela do Presidente da República, do Instituto Brasileiro de Reforma Agrária (IBRA), com um capítulo específico aos contratos agrários. No dia 14 de novembro do mesmo ano, o Decreto n. 59.566 regulamentou as Seções I, II e III do Capítulo IV do Título III da Lei n. 4.504 e o Capítulo III da Lei n. 4.947.

O Decreto-Lei n. 1.110, de 9 de julho de 1970, extinguiu o IBRA e o Instituto Nacional de Desenvolvimento Agrário (INDA) e criou o Instituto Nacional de Colonização e Reforma Agrária (Incra), sujeito ao Ministério da Agricultura. É curioso que as ações governamentais, no tocante à reforma agrária, gradativamente vão se esvaindo em meio à prioridade aos Programas de Colonização e ao processo de aperfeiçoamento do aparato legal de sustentação dos contratos agrários. A política agrícola passou a ganhar cada vez mais relevância dentro da agenda do governo.

No caso específico dos contratos agrários,

[...] os usos e costumes regionais, mesmo sendo contrários aos interesses do contratante sem terra, prevalecem ou funcionam mais que a lei. 
O desconhecimento do Estatuto da Terra e da legislação regulamentar e complementar por parte do arrendatário e do parceiro outorgado, permitem o não cumprimento dos dispositivos quem visam a beneficiá-los (SODERO, 1979, p. 18).

A Lei n. 5.868/72 proporcionou certo respaldo aos dispositivos existentes de modo a controlar os contratos agrários. Os contratantes, porém, continuam alheios aos termos legais e o Incra vem perdendo o controle de tais contratos. ${ }^{6}$ Isso se nota pelo número expressivo de contratos orais, feitos com base em relações de confiança e sem grandes perspectivas no Brasil. O intuito da próxima seção é analisar o desenho, a estrutura e o desempenho desses contratos.

\section{Aspectos gerais E ClASSIFICAÇÃO dOS CONTRATOS DE ARRENDAMENTO}

Sabe-se que o direito agrário brasileiro classifica os contratos agrários em nominados ou inominados, típicos ou atípicos. Os contratos inominados e atípicos são aqueles que não estão expressamente previstos pela lei, mas visam disciplinar relações que têm como fim direto ou indireto a atividade agropecuária. Esses contratos existem em diferentes regiões do país e são celebrados conforme os costumes locais.

O “foreiro" e a "meação”, nas lavouras canavieiras do Nordeste, são exemplos clássicos desses contratos. Essas formas de exploração da terra encerravam um forte vínculo extraeconômico de subordinação do trabalhador ao proprietário, seja pela falta de autonomia do trabalhador, que só poderia plantar e vender conforme as determinações do proprietário; seja pela própria reprodução do processo, que impedia o trabalhador de adquirir certa independência econômica. A prestação de um dia de trabalho gratuito ao proprietário (renda-trabalho) recebia o nome de "foro" e o pagamento em produtos pelo uso da terra (renda-produto) meação (GUIMARÃES, 1968; CARNEIRO, 1978).

Barroso (2001) subclassificou as duas novas espécies contratuais agrárias, a saber, "leasing agrário" e "arrendamento rural com opção de compra", 7 como contratos atípicos mistos compostos de duas ou mais formas típicas. De um lado, o arrendamento rural com opção de compra poderia ser incluído entre os nominados e típicos, tendo em vista sua identidade com o arrendamento rural, se a opção de compra ou de aquisição de cessão de direitos de posse estivesse no ordenamento jurídico. Assim, é cabível classificá-lo como inominado. De outro, não se trata de um contrato essencialmente atípico, pois apresenta certa semelhança, na sistemática jurídica, com o arrendamento rural. Para o autor, o arrendamento rural com opção de compra agrega novos elementos. É um contrato misto que consubstancia elementos do arrendamento rural (cessão de direitos de posse, atividade agrária) e elementos intrínsecos ao arrendamento mercantil (a troca, a compra). O leasing agrário, por seu turno, acompanha essa mesma orientação. 
É oportuna a ressalva que, dentre as justificativas para a criação do leasing agrário e do arrendamento rural com opção de compra, está uma de caráter objetivo: a função social da propriedade. Nas palavras do mesmo Barroso citado acima, "visam a garantir ao arrendatário, uma vez expirado o prazo de vigência do contrato, a aquisição da propriedade ou da cessão dos direitos de posse inerentes ao imóvel rural objeto do arrendamento" (p. 76).

Por conseguinte, os contratos nominados e típicos são aqueles que a legislação agrária consagrou como formas típicas de uso e posse temporária da terra. No caso brasileiro, o arrendamento e a parceria, em suas diferentes modalidades. Passemos à análise de cada uma dessas relações contratuais.

\section{I Aspectos gerais}

\section{I. I FORMA}

Os contratos agrários, notadamente, os de arrendamento ou parceria, podem ser escritos ou verbais. Caso seja verbal, presume-se ajustado às cláusulas obrigatórias, conforme prescreve o art. 11 do Decreto n. 59.566/66. Se for escrito, expressa um meio de prova contratual, e não um elemento de sua formação. Embora a forma escrita não seja uma imposição, a legislação agrária, no $\S 2^{\circ}$ do art. 11 do Decreto, faculta a cada parte contratante a possibilidade de exigir da outra a celebração do contrato por escrito, como medida de segurança. No concernente às despesas, devem correr pelo modo que convencionarem os contratantes.

Hironaka observou que a:

[...] dispensa do formalismo, do documento escrito, resulta, sem dúvida, na atenção conferida pelo legislador à praxe do agro, pois no campo, via de regra, impera o analfabetismo, especialmente no tocante à figura daquele considerado economicamente menos favorecido (1990, p. 103).

Pode-se pensar que o legislador, atento a amparar ambas as formas contratuais, procurava dar incentivos à prática dos contratos agrários. De fato, a maioria dos contratos de arrendamento e parceria no Nordeste e, em outras regiões do país, é verbal e está sujeita a relações de amizade e confiança.

\section{2. i. 2 Prazos}

No Código Civil, não se vê uma preocupação nem de zelar pela estabilidade do arrendatário ou parceiro na atividade agrária, nem de conciliar o prazo contratual com as especificidades próprias de cada ciclo biológico. O Estatuto da Terra procurou superar essas falhas e fixou prazos mínimos para os contratos agrários. O art. 95, I e II, do presente Regulamento estabelece: 
I - os prazos de arrendamento terminarão sempre depois de ultimada a colheita, inclusive a de plantas forrageiras temporárias cultiváveis. No caso de retardamento da colheita por motivo de força maior, considerar-se-ão esses prazos prorrogados nas mesmas condições, até sua ultimação;

II - presume-se feito, no prazo mínimo de três anos, o arrendamento por tempo indeterminado, observada a regra do item anterior.

O Decreto n. 59.566/66, contudo, dispõe no art. 13, II, “a”, sobre os prazos mínimos nos contratos agrários: a) três anos, para os casos de arrendamento em que ocorra atividade de exploração de lavoura temporária e ou de pecuária de pequeno e médio porte; ou em todos os casos de parceria; b) cinco anos, para os casos de arrendamento em que ocorra atividade de exploração de lavoura permanente e ou de pecuária de grande porte para cria, recria, engorda ou extração de matérias primas de origem animal; e c) sete anos, para os casos de arrendamento em que ocorra atividade de exploração florestal.

No tocante ao contrato de parceria, o art. 13, II, “a”, e o art. 37 (“As parcerias sem prazo convencionado pelas partes, presumem-se contratadas por três anos”) do Decreto dispõem a posição da legislação agrária. O Estatuto da Terra de igual maneira dispõe, no art. 96, I, “o prazo dos contratos de parceria, desde que não convencionados pelas partes, será no mínimo de três anos, assegurado ao parceiro o direito à conclusão da colheita, pendente, observada a norma constante do inciso I, do artigo 95”.

No que diz respeito à prorrogação do prazo dos contratos agrários, a segunda parte do inciso I do art. 95 do Estatuto da Terra, em concordância com a segunda parte do $\S 1^{\circ}$ do art. 21 do Decreto, "Em caso de retardamento da colheita por motivo de força maior esses prazos ficarão automaticamente prorrogados até o final da colheita”.

Essa é a primeira hipótese de prolongamento do prazo, a segunda está expressa no $\S 3^{\circ}$ do art. 21 do Decreto: "o arrendamento que, no curso do contrato, pretender iniciar nova cultura cujos frutos não possam ser colhidos antes de terminado o prazo contratual, deverá ajustar, previamente, com o arrendador, a forma de pagamento do uso da terra por esse prazo excedente".

Diante desses dispositivos legais, levanta-se a pergunta: os prazos mínimos impostos pela lei abrangem as razões que motivaram a sua fixação? Oliveira argumentou que o legislador, ao determinar prazos mínimos obrigatórios, visava, em primeiro lugar, conservar os recursos naturais renováveis, "dentro do conceito de terra como bem de produção, na forma consagrada pela doutrina da função social da propriedade" (1988, p. 2). Em segundo lugar, pretendia dar estabilidade ao contratante não proprietário, ou seja, proporcionar o tempo necessário para o cultivador fixar-se na terra, preparar o solo, zelar pelo plantio e aguardar o período da colheita. 
Na realidade, todavia, nota-se uma falta de "aplicabilidade prático-formal" dos prazos mínimos aos contratos agrários típicos. O curto prazo dos contratos pode comprometer a sustentabilidade econômica, ambiental e social do arrendamento e da parceria. Economicamente, o produtor procura extrair o máximo da terra sem a necessidade de dispêndio de muitos recursos na manutenção de sua qualidade. Em termos ambientais, há um desinteresse por parte dos produtores em adotar técnicas de conservação (o plantio direto, por exemplo), pois exigem a realização de um montante mais expressivo de investimentos. Eles sabem, pela experiência, que a possibilidade de retorno é mínima durante a vigência do contrato. Por último, o impacto social é reflexo dos dois antecedentes. Os prazos dos contratos nem sempre são suficientes para obter a renda necessária ao sustento do produtor e de sua família.

Sob a ótica do proprietário, os prazos mínimos constituem não somente uma maneira de retomar em um período relativamente curto a posse de sua terra e evitar que o produtor, suposto beneficiário de reforma agrária, possa adquirir certa estabilidade no imóvel; mas ainda uma medida para conhecer os atributos não observáveis de seus arrendatários ou parceiros-outorgados.

\subsection{Arrendamento}

\subsection{CONCEITO}

O arrendamento é uma relação clara, que se assemelha ao aluguel de um imóvel, à locação de um automóvel, e por meio da qual uma parte cede à outra o uso de determinado bem, móvel ou imóvel, sob determinadas condições de tempo, utilização, manutenção e remuneração. No ambiente institucional brasileiro, o arrendamento de propriedades rurais é menos utilizado e conhecido do que em outros países, notadamente na Ásia e mesmo nos EUA. Em termos formais, o arrendamento rural é assim definido no Decreto n. 59.566/66, que regula a matéria.

Arrendamento rural é o contrato agrário pelo qual uma pessoa se obriga a ceder à outra, por tempo determinado ou não, o uso e gozo de imóvel rural, parte ou partes do mesmo, incluindo, ou não, outros bens, benfeitorias e ou facilidades, com o objetivo de nele ser exercida atividade de exploração agrícola, pecuária, agroindustrial, extrativa ou mista, mediante, certa retribuição ou aluguel, observados os limites percentuais da Lei (art. $3^{\circ}$ do Decreto n. 59.566/66).

\subsubsection{Sujeitos}

Os contratantes, ou sujeitos do arrendamento, são o arrendador (ou arrendante) e o arrendatário.

Denomina-se arrendador: 
[...] a pessoa física ou jurídica, proprietária ou não de imóvel rural, ou de partes ou parte dele - e do qual tenha sua livre disposição e administração - que cede por contrato de arrendamento rural a outrem, por tempo determinado ou não, o uso e gozo do mesmo imóvel, com ou sem benfeitorias, para nele ser exercida atividade agrária, mediante certa retribuição ou aluguel, observados os limites percentuais estabelecidos pela lei (SODERO, 1968, F. P., Enc. Saraiva do Direito, p. 47).

O arrendatário é:

[...] a pessoa física ou jurídica, ou chefe de família, representando o conjunto familiar, que recebe, no contrato agrário de arrendamento, imóvel rural, parte ou partes dele, com ou sem benfeitorias, por tempo determinado ou não, da outra parte denominada arrendante ou arrendador, com o fim de, nesse imóvel, exercer atividade agrária, mediante o pagamento de um aluguel ou renda, observados os limites percentuais estabelecidos na lei (SODERO, F. P., Enc. Saraiva do Direito, 1968, p. 103).

Pelos dispositivos legais pertinentes, a pessoa que cede o imóvel rural não necessariamente é o proprietário. Pode ser até mesmo o arrendatário, se tiver a livre disposição e administração do bem e autorização para contratar o subarrendamento. Alude-se a arrendatário não somente a pessoa física, mas também a categoria de pessoa jurídica, como no caso das usinas de açúcar (HIRONAKA, 1990).

\subsection{3 Овјето}

O objeto do contrato de arrendamento é o uso e o gozo do imóvel rural.

Visto que a propriedade da terra apresenta uma função social, o destino dado a esta deve ser para atender tal princípio, ou seja, desenvolver atividade agrária de forma eficiente e em consonância com o bem-estar social. Se a finalidade do arrendamento for a exploração de produtos agrícolas proibidos pela lei, por exemplo o plantio da maconha, o contrato será ilícito e sem validade jurídica.

O contrato de arrendamento deverá indicar seu objeto de maneira determinável, ou seja, por meio da identificação e descrição do imóvel, tipo de atividade agrária desenvolvida é possível saber a destinação do imóvel rural.

\subsubsection{Preço}

O principal objetivo de fixar um valor-limite seria impor um efetivo controle do Poder Público sobre o preço do arrendamento a fim de salvaguardar o economicamente frágil da especulação do proprietário, que nem sempre cultiva, mas explora, demasiadamente, o arrendatário. Este assume todo o ônus dos riscos da produção. 
O art. 95 do Estatuto da Terra e o art. 17 do Decreto n. 59.566 preveem o valor-limite de remuneração do arrendamento. O preço do arrendamento não poderá ultrapassar $15 \%$ do valor cadastral do imóvel, já levando em consideração as benfeitorias incluídas na composição do contrato. Exceto nos casos de arrendamento parcial, em que o objeto do contrato for o uso e o gozo de área especialmente escolhida para exploração de elevada rentabilidade, o limite percentual poderá atingir até 30\% do valor das áreas arrendadas.

É obrigatória a fixação do preço do arrendamento em dinheiro, estabelecida conforme os parâmetros legais. A forma de pagamento, contudo, pode ser em dinheiro ou em quantidade equivalente de frutos. ${ }^{8}$ É interessante apontar que o legislador parece acomodar as normas à realidade agrária brasileira, em que, na maioria dos contratos, o preço do arrendamento é fixado a partir do valor do produto a ser cultivado e existe um grande número de contratos informais. Este fenômeno encontra-se tanto nas lavouras de grãos quanto nas agroindústrias canavieiras e cítricas (GARCIA, 1996).

Por último, há que se fazer menção aos prazos de reajustamento do preço do arrendamento. A lei exige que o preço no contrato passe periodicamente por um reajuste. O Decreto n. 59.566/66 no art. 16 determina que "a renda anual dos contratos de arrendamento será ajustada pelas partes contratantes, tendo como limite o estabelecido no art. 95, inciso XII, do Estatuto da Terra", e dispõe, no $\S 1^{\circ}$, que os contratos poderão "ser anualmente corrigidos a partir da data da assinatura", e no $\S 2^{\circ}$, "nos casos em que ocorrer exploração de produtos com preço oficialmente fixado, a relação entre os preços reajustados e os iniciais, não poderá ultrapassar a relação entre o novo preço fixado para os produtos e o respectivo preço na época do contrato".

Observa-se a destreza da lei de salvaguardar o arrendador de possíveis prejuízos decorrentes, por exemplo, da inflação que deteriora o valor da moeda e da não contabilização das benfeitorias que atrapalha a valorização do imóvel. Ao mesmo tempo, essa medida constitui um empecilho para o arrendatário realizar novos investimentos na capacidade produtiva, pois nem sempre consegue usufruir dos benefícios.

\subsubsection{Subarrendamento}

$\mathrm{O}$ art. $3^{\circ}, \S 1^{\circ}$, do Decreto n. 59.566/66 prevê que o subarrendamento é "o contrato pelo qual o arrendatário transfere a outrem, no todo ou em parte, os direitos e obrigações do seu contrato de arredamento". Neste caso, quem cede o imóvel é subarrendador e a pessoa que recebe a sublocação é o subarrendatário. O parágrafo único do art. 31 do Estatuto da Terra dita que "resolvido ou findo o contrato, extingue de pleno o direito de subarrendamento, salvo disposição convencional ou legal em contrário".

Pelo art. 95, VI, ainda do Estatuto da Terra o subarrendamento só é permitido se há o consentimento do proprietário. O Decreto n. 59.566/66, no art. 31, reforça que "é vedado ao arrendatário ceder o contrato de arrendamento, subarrendar ou emprestar total ou parcialmente o imóvel rural, sem prévio e expresso consentimento 
do arrendador”. Esta infração contratual levará ao despejo do arrendatário, pois está entre as hipóteses que o permitem e lista o inciso V do art. 31 do Decreto. Posto que não existe uma relação de locação entre o arrendador e o subarrendatário, aquele não pode erigir ação contra este, mas pode fazê-lo contra o arrendatário.

\subsection{Parceria}

\subsection{Conceito}

Conforme art. $4^{\circ}$ do Decreto n. 59.566/66, a parceria rural

é o contrato agrário pelo qual uma pessoa se obriga a ceder a outra, por tempo determinado ou não, o uso específico de imóvel rural, de parte ou partes do mesmo, incluindo, ou não, benfeitorias, outros bens e ou facilidades, com o objetivo de nele ser exercida atividade de exploração agrícola, pecuária, agroindustrial, extrativa vegetal ou mista; e ou lhe entrega animais para cria, recria, invernagem, engorda ou extração de matérias primas de origem animal, mediante partilha de riscos do caso fortuito e da força maior do empreendimento rural, e dos frutos, produtos ou lucros havidos nas proporções que estipularem, observados os limites percentuais da lei.

A natureza jurídica do contrato de parceira é diferente do arrendamento rural. Para Vieira,

trata-se de uma sociedade sui generis, pois apresenta muitas características da relação societária: as partes se associam para exercitar em conjunto um empreendimento e a atividade comum comporta a assunção da responsabilidade pela gestão por parte de ambos. De fato, é estabelecido que os riscos inerentes à empresa são suportados em igual medida pelo parceiro-outorgante e pelo parceiro-outorgado; serão, por outro lado, repartidos os lucros segundo uma proporção previamente estabelecida no contrato e segundo a maior ou menor participação na atividade empreenditorial por parte do parceiro-concedente (1998, p. 43).

\subsubsection{Sujeitos}

$\mathrm{Na}$ parceria, os sujeitos associam terra, trabalho e capital, para usar na atividade agrária do imóvel rural. Os rendimentos e a produção obtidos são, ao final do contrato, partilhados; bem como os riscos do empreendimento, na proporção acordada, e em conformidade aos limites impostos pela lei.

Ambos contratantes são denominados parceiros, sendo que parceiro-outorgante é o cedente, proprietário ou não, que entrega os bens; e parceiro-outorgado, a pessoa 
ou o conjunto familiar, representado pelo seu chefe, que os recebe para os fins próprios das modalidades de parcerias (art. $4^{\circ}$, parágrafo único, Decreto n. 59.566/66).

O parceiro-outorgado, na maioria das vezes, é o cultivador direto; enquanto o parceiro-outorgante, quase sempre, concorre com o imóvel e as benfeitorias incluídas. Pode existir situações em que o parceiro-outorgante cede máquinas, animais de tração, sementes; os quais incidirão sobre os percentuais que lhe confere em relação ao resultado da atividade agrária.

\subsection{3 Овјето}

À semelhança do arrendamento rural, o objeto da parceria é o uso do imóvel rural. A diferença é que o objeto muda de acordo com a modalidade da parceria, ou seja, o uso do imóvel pode ser para exploração de atividade vegetal, animal, agroindustrial, extrativa ou mista.

\subsubsection{Modalidades}

A legislação vigente identifica no art. $5^{\circ}$, I a V, do Decreto n. 59.566/66 cinco modalidades de parceria rural.

I - Parceria Agrícola - quando o objeto da cessão for o uso de imóvel rural, de parte ou partes do mesmo, com o objetivo de nele ser exercida a atividade de produção vegetal.

II - Parceria Pecuária - quando o objetivo da cessão forem animais para cria, recria, invernagem ou engorda.

III - Parceria Agroindustrial - quando o objeto da sessão for o uso do imóvel rural, de parte ou partes do mesmo, ou maquinaria e implementos, com o objetivo de ser exercida atividade de transformação de produto agrícola, pecuário ou florestal.

IV - Parceria Extrativa - quando o objeto da cessão for o uso de imóvel rural, de parte ou partes do mesmo, e ou animais de qualquer espécie, com o objetivo de ser exercida atividade extrativa de produto agrícola, animal ou florestal.

V - Parceria Mista - quando o objeto da cessão abranger mais de uma das modalidades de parceria definidas nos incisos anteriores.

\subsubsection{Partilha dos frutos, produtos, lucros e riscos}

Fala-se que a parceria rural é uma sociedade particular. Os contratantes partilham os 
riscos e os resultados da produção de modo proporcional e nos limites da lei. O controle do Poder Público é feito via fixação dos percentuais na partilha dos frutos alcançados. O legislador cuidou de estabelecer a quota máxima do parceiro-outorgante segundo sua menor ou maior participação na atividade produtiva de acordo com o art. 35 do Decreto n. 59.566/66.

I - 10\% (dez por cento) caso concorra somente com a terra nua;

II - 20\% (vinte por cento) se concorrer com a terra preparada e moradia;

III - 30\% (trinta por cento) se concorrer com o conjunto básico de benfeitorias, constituído especialmente de casa de moradia, galpões, banheiro para gado, cercas, valas ou currais, conforme o caso;

IV - 50\% (cinquenta por cento), quando concorrer com a terra preparada e o conjunto básico de benfeitorias enumeradas no inciso III, e mais o fornecimento de máquinas e implementos agrícolas, para atender aos tratos culturais, bem como as sementes e animais de tração e, no caso de parceria pecuária, com animais de cria em proporção superior a 50\% (cinquenta por cento) do número total de cabeças objeto da parceria;

$\mathrm{V}-75 \%$ (setenta e cinco por cento), nas zonas de pecuária ultraextensiva, em que forem os animais de cria em proporção superior a 25\% (vinte e cinto por cento) do rebanho onde se adotem a meação do leite e a comissão mínima de 5\% (cinco por cento) por animal vendido.

A partilha dos frutos e a divisão de riscos podem constituir um incentivo para as partes contratantes. Estas sabem que o montante de sua receita depende diretamente dos retornos obtidos com a safra. O parceiro-outorgante, observando a capacidade e os esforços do parceiro-outorgado, a elevação da produtividade e a honradez ao pagamento pelo uso do imóvel rural, não se interessa pelo término ou mudança do contrato.

\subsubsection{FAlsa PARCERia}

A prática da falsa parceria é uma situação relativamente comum nas áreas rurais. Consiste em um contrato que o proprietário cede a terra, moradia, animais, sementes, máquinas, inseticidas, e, às vezes, dinheiro. E o outro contratante cede somente o seu trabalho.

Hironaka (1990) sublinhou duas características da falsa parceria. A primeira delas é a remuneração do trabalhador. Uma parte do salário será pago em dinheiro e a 
outra equivalente a um percentual dos frutos da lavoura ou dos animais. A segunda característica é que a direção, o custeio e os riscos do empreendimento estão sob responsabilidade exclusiva do proprietário. Este contrato esconde, sob a aparência de parceria, uma relação empregatícia. Objetiva tão somente evitar os encargos da legislação trabalhista.

Ou melhor:

O que distingue a parceria da falsa parceria não é o fato do trabalhador receber sua remuneração parte em dinheiro e parte em frutos. A falsa parceria é a clara intenção de ocultar por trás de um suposto contrato de parceria o que em realidade é um contrato de trabalho (PETTERSEN; MARQUES, 1977, p. 40).

Além disso, pode-se dizer que a falsa parceira ocultaria um possível contrato de arrendamento. O proprietário cederia a terra e todos os equipamentos e implementos agrícolas; o trabalhador, que cederia o seu trabalho, tal como o arrendatário, estaria sujeito aos ditames do processo produtivo. As exigências da atividade produtiva e as habilidades administrativas poderiam ficar a cargo do trabalhador, que teria as mesmas responsabilidades de um arrendatário.

\subsection{DireITO DE PREFERÊNCIA OU PREEMPÇÃO}

No escopo deste artigo, vê-se a aplicação do direito de preferência, essencialmente nos casos de alienação do imóvel rural e de renovação contratual.

É preciso atentar que a legislação cível brasileira inscreveu o direito de preferência dentre as cláusulas especiais ao contrato de compra e venda, assim expresso no Código Civil de 2002:

Art. 513. A preempção, ou preferência, impõe ao comprador a obrigação de oferecer ao vendedor a coisa que aquele vai vender, ou dar em pagamento, para que este use de seu direito de prelação na compra, tanto por tanto.

Parágrafo único. O prazo para exercer o direito de preferência não poderá exceder a cento e oitenta dias, se a coisa for móvel, ou a dois anos, se imóvel.

O Estatuto da Terra estabelece que o direito de preferência é outorgado ao arrendatário e ao parceiro em virtude dos princípios gerais que regulamentam os contratos agrários. O objetivo é a proteção social e econômica desses trabalhadores, além da proteção dos recursos naturais. Almeida., ao tratar do direito de preferência em contratos agrários em trabalho publicado em 1987, comentou a respeito do tema nos seguintes aspectos: 
A preempção cabe não só na hipótese de alienação do imóvel rural, objeto do contrato, como também, na renovação contratual, quando, em igualdade de condições com estranhos, os contratantes outorgados terão preferência: na parceria, por previsão do art. 96, II, do Estatuto da Terra e por remissão do art. 34 de seu Regulamento, o Decreto 59.566/66; e, no arrendamento, por previsão do art. 95, IV, do Estatuto da Terra e art. 22 do Regulamento (1987, p. 120).

No Estatuto da Terra temos:

Art. 92. A posse ou uso temporário da terra será exercido em virtude de contrato expresso ou tácito, estabelecido entre o proprietário e os que nela exercem atividade agrícola ou pecuária, sob forma de arrendamento rural, de parceria agrícola, pecuária, agroindustrial e extrativa, nos termos desta Lei.

$\S 1^{\circ}(\ldots)$

$\S 2^{\circ}(\ldots)$

$\S 3^{\circ}$ No caso de alienação do imóvel arrendado, o arrendatário terá preferência para adquiri-lo em igualdade de condições, devendo o proprietário dar-lhe conhecimento da venda, a fim de que possa exercitar o direito de preempção dentro de trinta dias, a contar da notificação judicial ou comprovadamente efetuada, mediante recibo.

$\S 4^{\circ} \mathrm{O}$ arrendatário a quem não se notificar a venda poderá, depositando o preço, haver para si o imóvel arrendado, se o requerer no prazo de seis meses, a contar da transcrição do ato de alienação no Registro de Imóveis.

$\S 5^{\circ} \mathrm{A}$ alienação ou a imposição de ônus real ao imóvel não interrompe a vigência dos contratos de arrendamento ou de parceria ficando o adquirente sub-rogado nos direitos e obrigações do alienante.

A legislação agrária é clara. O proprietário que deseja alienar o seu imóvel deve enviar uma notificação ao arrendatário, por via judicial, ou por outro meio também idôneo e seguro. Na hipótese da comprovação regular da notificação, o arrendatário terá prazo de trinta dias para exercer seu direito de preferência. "Caso deixe transcorrer in albis tal prazo, surge a presunção de que renunciou ao direito, ou não ser de seu interesse a aquisição do imóvel, ou por não ter condições para igualar a oferta efetuada ao proprietário." (GRASSI NETO, 1994, p. 116). 
Se a notificação omitir as condições de pagamento, presume-se à vista. À falta de notificação, ou havendo sido operada de forma viciada, ou com dúvida de recebimento, o arrendatário ou o parceiro-outorgado poderá exercer o direito de preferência, também denominado de preempção ou de adjudicação compulsória.

A lei estabeleceu o prazo de seis meses para o efetivo exercício desse direito, fixando seu início na data de transcrição da escritura de compra e venda no Registro de Imóveis, decorrido o qual a venda, embora inicialmente viciada, se convalida (VIEIRA, 1998, p. 38).

Se existir um imóvel com mais de um arrendatário, a legislação prevê que qualquer um deles poderá exercer o direito de prelação, por inteiro, desde que os demais não queiram. Caso contrário, todos terão a preferência segundo sua área de arrendamento. Em hipótese de alienação parcial do imóvel, só o trabalhador que exerce sua atividade no local terá o direito de preferência.

O direito de preferência quanto à renovação do contrato é, indistintamente, aplicável ao contrato de arrendamento e parceria, conforme previsto pelo art. 95, IV e V, do Estatuto da Terra:

IV - em igualdade de condições com estranhos, o arrendatário terá preferência à renovação do arrendamento, devendo o proprietário, até 6 (seis) meses antes do vencimento do contrato, fazer-lhe a competente notificação extrajudicial das propostas existentes. Não se verificando a notificação extrajudicial, o contrato considera-se automaticamente renovado, desde que o arrendador, nos 30 (trinta) dias seguintes, não manifeste sua desistência ou formule nova proposta, tudo mediante simples registro de suas declarações no competente Registro de Títulos e Documentos;

$\mathrm{V}$ - os direitos assegurados no inciso IV do caput deste artigo não prevalecerão se, no prazo de 6 (seis) meses antes do vencimento do contrato, o proprietário, por via de notificação extrajudicial, declarar sua intenção de retomar o imóvel para explorá-lo diretamente ou por intermédio de descendente seu.

Pode-se comentar que tanto na hipótese de venda quanto de renovação contratual o direito de preferência previsto no Estatuto da Terra constitui uma garantia contraditória; pois, se no prazo de seis meses anteriores ao encerramento do contrato o proprietário enviar uma notificação ao arrendatário da intenção de dispor do imóvel para explorá-lo diretamente, o direito de preferência não subsistirá. 
Por fim, Grassi Neto (1994) chamou a atenção para o fato que uma leitura literal dos textos legais pode persuadir-nos a afirmar que a preferência na compra de imóvel rural, objeto de contrato agrário, recai exclusivamente em caso de arrendamento, não considera a parceria e o subarrendamento. Isso pode ser visto no art. 92, $\S 3^{\circ}$ do Estatuto da Terra, transcrito acima, e no art. 45 do Decreto n. 59.566:

Art. 45. Fica assegurado a arrendatário o direito de preempção na aquisição do imóvel rural arrendado. Manifestada a vontade do proprietário de alienar o imóvel, deverá notificar o arrendatário para, no prazo, de 30 (trinta) dias, contado da notificação, exercer o seu direito.

Igualmente, Opitz e Opitz (1971) consideraram que, conforme previsto no Estatuto da Terra, o direito de preferência abrange, exclusivamente, os arrendatários; não reconhece o direito de preferência aos imóveis rurais dados em parceria. Sodero também pensava que não era de difícil compreensão o não cabimento do direito de preempção à parceria, porque se trata de um contrato de parceria, "se uma das partes, o cedente, se retira, o contrato se extingue, com a obrigação de ressarcir a outra, das perdas e danos causados” (1968, p. 133).

A mesma linha de pensamento segue Hironaka, para quem:

[...] a parceria, sociedade sui generis que é, não permite vislumbrar tal circunstância beneficiadora ao parceiro-outorgado. Em caso de venda do imóvel dado em parceria, extingue-se o contrato, com as consequências que a lei determina, no que concerne ao ressarcimento de perdas e danos (1990, p. 119).

Pettersen e Marques, contudo, contestaram que não existe nada no Estatuto da Terra, nem em seu Regulamento, para impedir os parceiros de exercerem o direito de preferência, conforme expressaram nos seguintes termos:

A proteção social e econômica não é privilégio apenas dos arrendatários. $\mathrm{O}$ direito de acesso à terra àqueles que nela trabalham, garantindo a permanência no solo trabalhado, não pode restringir-se apenas aos arrendatários, sob pena de não garantir-se o uso econômico da terra, protegendo o seu uso temporário e impedindo que a terra vá cair em mãos de terceiros estranhos à relação contratual [...] (1977, p. 55).

Apreende-se que o direito de preferência pode, em certas situações, introduzir dificuldades contratuais para a venda do imóvel, uma vez que o proprietário necessitará consultar o arrendatário sobre seu interesse e este poderá tardar para contestar, 
gerando certa insegurança em relação à venda para terceiros. Além disso, é comum, em negócios de terras, que as propriedades sejam inseridas como parte de transações maiores e o direito de preferência pode, nestes casos, significar um entrave para a realização da principal transação. O fato é que, ainda que o direito de preferência constitua uma justa garantia a quem explora economicamente o imóvel rural quando da alienação do bem ou renovação do contrato, muitos proprietários evitam arrendar terras para não poder delas dispor em seus negócios sem a obrigação de transacionar com o arrendatário.

\subsection{INDENIZAÇÃO POR BENFEITORIAS}

De maneira geral, as benfeitorias que forem feitas no imóvel rural pelo arrendatário e ou pelo parceiro-outorgado são passíveis de indenização, no ato da extinção ou rescisão dos contratos de arrendamento e parceria. O art. 24, I, II e III, do Decreto n. 59.566/66 define basicamente três categorias de benfeitorias: voluptuárias, úteis e necessárias.

As voluptuárias são aquelas relacionadas ao deleite ou recreio, que não elevam o uso habitual do imóvel rural, embora o tornem mais agradável ou sejam de maior valor. As úteis aumentam ou facilitam o uso do imóvel rural. E as necessárias têm a finalidade de conservar o imóvel ou evitar que se deteriore, bem como cumprir as normas estabelecidas no Decreto para a preservação dos recursos naturais.

$\mathrm{O}$ arrendatário e/ou parceiro-outorgado que realizarem benfeitorias úteis e ou necessárias no imóvel rural terão direito à indenização, conforme a regra do direito comum. Já a benfeitoria voluptuária somente será indenizada quando o arrendador expressamente autorizar. Em virtude disso, Opitz e Opitz apontaram a importância da caracterização exata do tipo de benfeitoria para evitar equívocos. Alertaram que "mister se torna verificar as circunstâncias regionais, porque, muitas vezes, uma benfeitoria é voluptuária num ponto e útil noutro" (1969, p. 246).

Por um lado, pelo art. $25, \S 1^{\circ}$, do Regulamento, assegura-se a permanência no imóvel rural ao arrendatário e ao parceiro-outorgado, enquanto não receberem indenização por benfeitorias necessárias e úteis, no uso e gozo de todas as vantagens por ele oferecidas, nos termos das cláusulas contratuais.

Por outro lado, "quando as benfeitorias necessárias ou úteis forem feitas às expensas do arrendador dando lugar a aumento nos rendimentos da gleba, terá ele direito a uma elevação proporcional da renda, e não serão indenizáveis ao fim do contrato, salvo estipulação em contrário" (art. 25, § 2 , Decreto n. 59.566/66). O Regulamento, entretanto, no art. $17, \S 5^{\circ}$, dispõe que o preço do arrendamento das benfeitorias, incluídas na composição do contrato, não poderá ultrapassar $15 \%$ do valor destas. Opitz e Opitz, perspicazmente, interpretaram que essa "regra se coaduna com o art. 95, XII do Estatuto da Terra, em que o preço do arrendamento não poderá ser superior a $15 \%$ do valor cadastrado do imóvel, incluídas as benfeitorias que entrarem na composição do contrato” (1969, p. 246). 
Pode-se afirmar que as benfeitorias permitem a elevação do preço do arrendamento. Marx (1985), em sua teoria da renda fundiária, já retratava o desinteresse dos arrendatários de realizar investimentos em obras de infraestrutura com longo prazo de depreciação (canais de drenagem e irrigação, por exemplo). Isso se devia, sobretudo, explica o autor, ao fato de as benfeitorias proporcionarem ao proprietário vantagens no momento de fixação do preço do arrendamento. Secundariamente, na maioria das vezes, os arrendatários não conseguem usufruir dos resultados da realização de benfeitorias, em razão do curto prazo dos contratos.

\section{CONSIDERAÇÕES FINAIS}

Este artigo considerou que duas instituições, especificamente direitos de propriedade e contratos, têm papel decisivo sobre a prática do arrendamento e da parceria no Brasil.

Os direitos de propriedade privada apresentam atributos que os tornam instituições estratégicas na alocação dos recursos. Esses direitos definem as restrições e os limites de utilização do imóvel, prestam para coordenar as ações dos indivíduos, evitar conflitos custosos, diminuir a incerteza e os desincentivos aos investimentos e à inovação tecnológica. A propriedade privada da terra afeta substancialmente as ações dos arrendatários e parceiros, posto que a segurança do título e a forma de acesso à terra repercutem diretamente sobre as decisões de uso dos recursos e, por conseguinte, sobre sua rentabilidade.

Os contratos, por sua vez, são instituições por meio das quais se determinam que tipo de direitos de propriedade podem ser transferidos, e em que termos. A escolha de um contrato dependerá de uma negociação voluntária entre as partes. Quando os contratos não são voluntários nem são cumpridos automaticamente, é preciso que as instituições estabeleçam regras adequadas para promover e garantir a assinatura e o cumprimento destes.

Os contratos podem ser formais e informais. Os primeiros são escritos conforme a lei e seu cumprimento é obrigatório; os últimos são válidos apenas pela força da tradição, usos e costumes e as partes obedecem sem a necessidade do Poder Público. A elaboração do contrato compreende basicamente o desenho e a vigilância. O desenho incorpora a corresponsabilidade nos custos e benefícios, o cumprimento automático e a confiança. Já a vigilância contém as cláusulas preventivas e não punitivas (ALMEIDA, 2002; BUAINAIN et al, 2007).

De modo particular, o artigo buscou na legislação agrária brasileira a presença, ou não, de incentivos aos contratos de arrendamento e parceria no Brasil. No início, esses contratos atendiam basicamente três funções: conservação da grande propriedade, suprimento à carência de alimentos e substituição do trabalho escravo. Isso se traduzia em um mecanismo para solucionar os problemas decorrentes da manutenção de 
terras improdutivas e da falta de mão de obra por parte dos proprietários, assim como da necessidade de aumentar a produção de alimentos.

Somente com o Código Civil Brasileiro de 1916 que os contratos de arrendamento e parceria tornaram-se juridicamente ordenados. Apesar dos avanços na regulamentação dessas relações contratuais, o país não possuía uma legislação majoritariamente agrária, o que causava enormes deficiências no desenho, estabelecimento e desempenho dos contratos agrários. A criação do Estatuto da Terra em 1964, as leis e os decretos posteriores deram novo vigor aos dispositivos legais pertinentes à matéria.

O custo da atividade produtiva (i.e., preço do arrendamento mais custos de produção) sempre se mostrou muito alto para os arrendatários. A diminuição da rentabilidade, notadamente nos momentos de crise agrícola (quebra de safra, redução de preços dos produtos, por exemplo), impede que a maioria desses produtores consiga arcar com as despesas da produção.

O curto prazo dos contratos é um obstáculo à realização de novos investimentos por parte dos pequenos arrendatários. Esses produtores dificilmente conseguem acompanhar as constantes exigências do setor, como a redução rápida e contínua do custo de produção, adoção de práticas agrícolas modernas e adequadas à atividade produtiva, aperfeiçoamento das habilidades administrativa e empresarial. A convergência desses fatores impede que os produtores sejam capazes de fixar um preço mais competitivo para seus produtos.

No concernente à parceria, há que se destacar dois aspectos: partilha dos frutos e divisão de riscos. A legislação prevê a quota máxima do parceiro-outorgante conforme sua participação na atividade produtiva. A recompensa para o maior esforço, empenho do parceiro-outorgado, advém da sua parcela da produção. A possibilidade de dividir os riscos com o proprietário pode constituir um incentivo para realizar investimentos na capacidade produtiva.

Ainda em relação à parceria, os contratos podem adquirir características de um contrato de trabalho. Os mercados de trabalho apresentam elevados riscos (i.e., encargos trabalhistas), e a falsa parceria poderia ser um instrumento para diminui-los. Ademais, assume-se que o trabalho assalariado reduz o esforço no processo produtivo em razão do pagamento fixo, mas a perspectiva da partilha dos frutos inerente à parceria constitui um incentivo ao trabalho.

Percebe-se que os dispositivos legais apresentam muitas contradições. Essas tomam relevo, pois nem sempre as cláusulas contratuais conseguem amparar a parte economicamente mais frágil. Um exemplo elucidativo disso é o direito de preferência no que se refere à renovação contratual. Sabe-se que no prazo de seis meses que antecedem o término do contrato o proprietário pode mandar uma notificação ao arrendatário manifestando seu intento de dispor do imóvel para explorá-lo diretamente. Assim, o direito de preferência previsto no Estatuto da Terra não se aplica ao contrato de arrendamento. 
As experiências em algumas regiões do país (Triângulo Mineiro e Alto Paranaíba, por exemplo) mostram um frequente burlamento dos contratos, embora estejam regulamentados pela lei. Os prazos são diluídos em favor de interesses pontuais dos proprietários, principalmente a recuperação de solos degradados e ocupação de áreas passíveis de conflitos agrários.

Reconhece-se a necessidade de fazer benfeitorias no imóvel rural para melhorar os resultados da produção. No entanto, são latentes as preocupações dos produtores, pois têm dúvida se irão usufruir completamente dos benefícios, em decorrência, principalmente do curto prazo dos contratos. Além disso, as benfeitorias, quase sempre, elevam o preço do arrendamento, o que é um desincentivo para os arrendatários.

Portanto, torna-se necessário pensar políticas públicas que promovam mudanças na legislação, de maneira a assegurar melhores condições produtivas e financeiras aos arrendatários e parceiros, especialmente os pequenos produtores que têm difícil acesso à terra e aos demais mercados (i.e., insumos, comercialização, crédito rural).

: ARTIGO APROVADO (15/05/2013) : RECEBIDO EM 29/06/2010

\section{NOTAS}

1 Este é o caso da Economia Neoclássica. Visto que os agentes têm racionalidade ilimitada e informação simétrica, as relações contratuais não estão sujeitas a atitudes oportunistas. Cabe lembrar que os dois pressupostos comportamentais para a existência dos custos de transação são a racionalidade limitada e o oportunismo. Na ausência desses pressupostos, não há custo de obtenção e defesa dos direitos de propriedade, e eles serão perfeitamente definidos e completamente seguros. Os neoclássicos não os consideram explicitamente na análise, pois os bens são automaticamente alocados de maneira que maximizam o bem-estar.

2 É preciso sublinhar que o acesso à terra no período colonial não era exclusivo para quem obtinha a sesmaria. Durante mais de três séculos (entre 1500 e 1822) o acesso legal à terra dava-se por concessão, por parte da Metrópole portuguesa, da carta de sesmaria. Conforme Benatti (2003), esse mecanismo privilegiava as pessoas conhecidas como "de bem e de posse" (i.e., os nobres, o clero da Igreja e a burguesia nascente). Após a Independência do Brasil, o regime sesmarial foi extinto e o país ficou sem uma legislação para regulamentar o acesso à terra. Até o surgimento da Lei de Terras (Lei n. 601 de 18 e setembro de1850), a posse da terra era facilmente realizada sem uma autorização oficial. "No período colonial, uma das principais formas de apropriar-se da terra e dos recursos naturais deu-se por meio do apossamento primário da terra e dos recursos naturais renováveis, com base em uma agricultura móvel, predatória e rudimentar" (p. 54).

3 Para Furtado (1972), os problemas estruturais do desenvolvimento econômico brasileiro advêm de nossa agricultura itinerante.

4 "Muito embora as ordenações hajam seguido, em tese, o princípio romano do Código, de que o arrendamento apenas gera uma relação particular entre locador e locatário (liv. 4, tit. $9^{\circ}$ ), no entanto, quando se trata de locação por mais de dez anos dá-lhe outra fisionomia, passando em tal caso a ser considerada como um contrato enfitêutico. 
No Direito romano, aliás, ao lado da enfiteuse, havia também os arrendamentos a longo prazo, considerados por alguns autores como fonte da própria enfiteuse.

Com o alvará de 3 de novembro de 1857 e lei de 4 de julho de 1776 a locação foi reduzida à condição de contrato pessoal, 'ainda que fosse de cem anos'." (MEIRA, 1983, p. 120)

5 O Estatuto do Trabalhador Rural data de 1963.

6 "Cada qual faz o contrato como melhor entende e se surge conflito e as partes vão a juízo, busca o Magistrado - se conhece a lei agrária - adaptá-lo às normas vigentes, dentro do espírito que disciplina as avenças em apreço.” (SODERO, 1979, p. 18-19).

7 O leasing agrário seria o contrato mediante o "qual a arrendadora, pessoa jurídica, adquire a propriedade ou os direitos de posse sobre o imóvel rural que, em seguida, arrenda ao rurícola ou à empresa agrária, facultando a estes, no término do prazo convencionado, exercer a opção de compra ou de aquisição da cessão dos direitos possessórios a ele inerentes" (BARROSO, 2001, p. 78). No que se refere à nova modalidade do arrendamento rural, segundo o mesmo autor, a principal diferença é a opção de compra, pois se trata de uma característica específica do arrendamento mercantil.

8 Segundo Marx (1985), a renda em dinheiro é a metamorfose da renda em produto. Se, por um lado, o produtor ainda produz a maior parte de seus meios de subsistência; por outro, necessita transformar seu produto em mercadoria e vendê-las para obter dinheiro, que, posteriormente, é destinado ao proprietário de terras a título de renda fundiária. A relação produtor e proprietário assume características contratuais.

\section{REFERÊNCIAS BIBLIOGRÁFICAS}

ALMEIDA, P. G. O direito de preferência nos contratos agrários. A atividade agropecuária como característica fundamental. Revista de Direito Civil, Imobiliário, Agrário e Empresarial, São Paulo, v. 11, n. 40, p. 118-22, abr./jun. 1987. ALMEIDA, P. J. de Arrendamento e Acesso à Terra no Brasil. Dissertação (Mestrado) - IE/UNICAMP, Campinas, 2002. BARROSO, L. A. Leasing agrário e arrendamento rural com opção de compra. Belo Horizonte: Del Rey, 2001. BENATTI, J. H. Direito de propriedade e proteção ambiental no Brasil: apropriação e uso dos recursos naturais no imóvel rural. Tese (Doutorado) - NAEA/UFPA, Belém, 2003.

BuAinain, A. M.; AlmeidA, P. J. de; LiMA, F. de; SilveirA, J. M. F. J. da. O Arrendamento de terras no Brasil: condicionantes, funcionamento e perspectivas. Brasília. Relatório de Pesquisa, 2007.

CAMARÇO, C. A. M. Contratos agrários: uma nova visão do sistema normativo. Revista de Direito Agrário, Brasília, v. 17, n. 16, p. 79-85, 2001.

CARNEIRO, R. C. Capitalismo e pequena produção na agricultura do Nordeste. Dissertação (Mestrado) IFCH/Unicamp, Campinas, 1978..

COASE, R. H. The nature of the firm. Economica, 1937.

The problem of social cost. Journal of Law and Economics Vol. 3, p. 1-44, The University of Chigago Press, 1960. (disponível em http://www.jstor.org/stable/724810)

FRANÇA, R. Limongi (Coord.). Enciclopédia Saraiva do Direito São Paulo: Saraiva, 1978.

FURTADO, C. Análise do modelo brasileiro. 3. ed. Rio de Janeiro: Civilização Brasileira, 1972.

GARCIA, A. R. Manual prático de arrendamento e parceria. São Paulo: Globo, 1996.

GRASSI NETO, R. O “direito de preferência” nos contratos agrários. Revista de Direito Civil, Imobiliário, Agrário e Empresarial, São Paulo, v. 18, n. 68, p. 108-123, abr./jun. 1994.

GUEDES PINTO, L. C. Reflexões sobre a política agrária brasileira no período 1964-1994. Reforma Agrária. Revista da ABRA, São Paulo, v. 25, n. 1, p. 65-92, 1995.

GUimarães, A. P. Quatro séculos de latifúndio. 3. ed. Rio de Janeiro: Paz e Terra, 1968.

HIRONAKA, G. M. F. N. Contratos agrários. Revista de Direito Civil, Imobiliário, Agrário e Empresarial, São Paulo, v. 14, n. 53, p. 100-121, jul./set. 1990.

MARX, K. O capital: crítica da economia política. São Paulo: Abril Cultural, 1985. (Coleção Os Economistas). MEIRA, Sílvio. Teixeira de Freitas o jurisconsulto do império: vida e obra. 2a. ed. revista e aumentada. Brasília: Cegraf, 1983. 
NORTH, D. Custos de transação, instituições e desempenho econômico. Rio de Janeiro: Instituto Liberal, 1994.

OLIVEIRA, L. M. Dos prazos mínimos nos contratos agrários típicos. Dissertação (Mestrado) - FD/USP, São Paulo, 1988. OPITZ, O.; OPITZ, S. C. B. (Contratos agrários no Estatuto da Terra. Rio de Janeiro: Editor Borsoi, 1969. OPITZ, O.; OPITZ, S. C. B. Contratos no direito agrário. Porto Alegre: Síntese, 1971.

PETTERSEN, A.; MARQUES, N. Uso e Posse temporária da terra (arrendamento e parceria). Doutrina, legislação, jurisprudência. São Paulo: Pró-Livro, 1977.

PRADO JR., C. A questão agrária no Brasil. São Paulo: Brasiliense, 1979.

SILVA, L. Terras devolutas e latifúndio: efeitos da Lei de 1850. Campinas: Editora da Unicamp, 1996.

SODERO, F. P. Direito agrário e reforma agrária. São Paulo. Ed. Livraria Legislação Brasileira, 1968.

O Estatuto da Terra, de 1964 a 1979. Reforma Agrária. Revista da ABRA, Campinas, São Paulo, v. 9, n. 6, p. 3-20, 1979.

SZTAJN, R. Law and economics. In: ZYLBERSZTAJN, D.; SZTAJN, R. (Orgs.). Direito e Economia: análise econômica do direito e das organizações. Rio de Janeiro: Elsevier, p. 74-83, 2005. 315 p.

; ZYLBERSZTAJN, D.; MUELLER, B. Economia dos direitos de propriedade. In: ZYLBERSZTAJN, D.;

SZTAJN, R. (Orgs.). Direito e Economia: análise econômica do direito e das organizações. Rio de Janeiro:

Elsevier, p. 84-136, 2005. 315p.

VIEIRA, I. A. Empresa agrária e contratos agrários. Revista dos Tribunais, São Paulo, v. 87, n. 757, p. 29-51, nov. 1998.

WILLIAMSON, O. Las instituciones económicas del capitalismo. México DF: Fondo de Cultura Económica, 1989.

Patrícia José de Almeida

Cidade Universitária "Zeferino Vaz" $\mathrm{s} / \mathrm{n}^{0}$ Distrito de Barão Geraldo - 13083-970 Campinas - SP - Brasil patricia.almeidadige.unicamp.br

Caixa Postal 6135 13083-970

Campinas - SP - Brasil buainaindeco.unicamp.br
Pesquisadora Pós-Doc do Instituto de Geociências (IG) no Departamento de Política Científica e Tecnológica (DPCT) da Universidade Estadual de Campinas (UNICAMP)

\section{Antônio Márcio Buainain}

PROFESSOR dO INSTITUTO DE ECONOMIA (IE) no Núcleo de EConomia Agrícola (NEA) da Universidade EstaduAL de CAMPINAS (UNICAMP) 
